\title{
Policy and public health recommendations to promote the initiation and duration of breast-feeding in developed country settings
}

\author{
Lisa Dyson ${ }^{1, *}$, Mary J Renfrew ${ }^{1}$, Alison McFadden ${ }^{1}$, Felicia McCormick', Gill Herbert ${ }^{2}$ \\ and James Thomas ${ }^{3}$ \\ 'Mother and Infant Research Unit, Department of Health Sciences, Area 4, Seebohm Rowntree Building, \\ University of York, Heslington, York YO10 5DD, UK: ${ }^{2}$ Gill Herbert Consultancy \& Development Ltd, Ashfield, \\ 20 Wood Lane, Newsome, Huddersfield HD4 6QG, UK: ${ }^{3}$ Nutritional Epidemiology Group, Faculty of Medicine, \\ Dentistry, Psychology and Health, University of Leeds, 30-32 Hyde Terrace, Leeds LS2 9LN, UK
}

Submitted 23 October 2008: Accepted 19 May 2009: First published online 18 August 2009

\begin{abstract}
Objective: To develop policy and public health recommendations for implementation at all levels by individuals and organisations working in, or related to, the field of breast-feeding promotion in developed country settings, where breastfeeding rates remain low.

Design: Two research phases, comprising (i) an assessment of the formal evidence base in developed country settings and (ii) a consultation with UK-based practitioners, service managers and commissioners, and representatives of service users. The evidence base included three systematic reviews and an Evidence Briefing. One hundred and ten studies evaluating an intervention in developed country settings were assessed for quality and awarded an overall quality rating. Studies with a poor quality rating were excluded. The resulting seventy studies examined twenty-five types of intervention for breast-feeding promotion. These formed the basis of the second consultation phase to develop the evidence-based interventions into recommendations for practice, which comprised (i) pilot consultation, (ii) electronic consultation, (iii) fieldwork meetings and (iv) workshops. Draft findings were synthesised for two rounds of stakeholder review conducted by the National Institute for Health and Clinical Excellence.

Results: Twenty-five recommendations emerged within three complementary and necessary categories, i.e. public health policy, mainstream clinical practice and local interventions.

Conclusions: The need for national policy directives was clearly identified as a priority to address many of the barriers experienced by practitioners when trying to work across sectors, organisations and professional groups. Routine implementation of the WHO/UNICEF Baby Friendly Initiative across hospital and community services was recommended as core to breast-feeding promotion in the UK. A local mix of complementary interventions is also required.
\end{abstract}

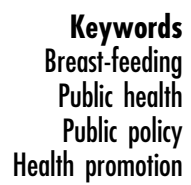

The short- and long-term benefits of breast-feeding to improve public health are widely recognised for both baby and mother ${ }^{(1-5)}$. Although initiation rates have increased in recent years, the UK has one of the lowest rates of breast-feeding worldwide, with initiation and duration rates remaining the lowest among families from lower socio-economic groups ${ }^{(6,7)}$. Similar national initiation rates of about $70 \%$ have also been reported for The Netherlands $^{(8)}$, France ${ }^{(9)}$ and the USA ${ }^{(10,11)}$.

Initiation rates, and to a lesser degree duration rates, are particularly low among white women in the UK compared with women who are Asian, black or of mixed origin $^{(6,7,12)}$. Teenage or young mothers have also been identified as a vulnerable group in terms of breast-feeding rates, being half as likely as older mothers to initiate any breast-feeding ${ }^{(6,7,12)}$. Indeed, mothers aged 20 years or under are the only group who have not experienced a significant increase in initiation rates between 2000 and 2005 in England and the $\mathrm{UK}^{(6)}$.

Women from some minority ethnic groups living in the UK, i.e. Asian and black women, have been shown to have lower rates of exclusive breast-feeding ${ }^{(13)}$ despite relatively high rates of initiation and duration of any breast-feeding ${ }^{(14)}$. This is in contrast to patterns in the 
USA, where the lowest rates of initiation and duration of any breast-feeding are lowest among non-Hispanic black mothers ${ }^{(14)}$.

These studies highlight the complex issues around the promotion of breast-feeding among different population groups within the UK and developed country settings, and the need to achieve an appropriate balance between provision of good-quality mainstream services for all women as well as specific services in accordance with local population needs.

The work reported here was initially commissioned by the former English Health Development Agency (HDA) to prepare national guidance on public health interventions to promote the initiation and duration of breast-feeding. The aim was to make recommendations for implementation in policy and practice at a local, regional and/or national level by individuals and organisations working in, or related to, the field of maternal and child health. The methods used aimed to ground the recommendations both in formal evidence of effectiveness and in practitioners', service managers', policy makers' and service users' views and experiences in the promotion of breast-feeding.

During the production of this guidance, the HDA was merged with the National Institute for Health and Clinical Excellence (NICE). The public health evidence-based recommendations for actions were published in an Evidence into Practice Briefing ${ }^{(15)}$ by NICE.

The purpose of the current paper is to present the complete policy and public health recommendations resulting from the analysis of evidence of effectiveness and the extensive consultation process. The recommendations aim to promote the initiation and/or duration of any and/or exclusive breast-feeding among healthy babies. Particular emphasis is given to the UK and developed country settings where breast-feeding rates are low.

\section{Methods}

The work comprised three main stages: (i) assessment and appraisal of the formal evidence base; (ii) consultation with practitioners, service managers and commissioners, and representatives of service users; and (iii) synthesis of draft findings which were then subject to two rounds of stakeholder review conducted by NICE. Full details of this methodology are provided elsewhere (reference 16; M Renfrew, L Dyson, A McFadden, J Thomas, F McCormick and $\mathrm{G}$ Herbert, unpublished results).

Briefly, the formal evidence base included three systematic reviews of interventions to increase the initiation and/or duration of breast-feeding ${ }^{(17-19)}$ and one Evidence Briefing to promote the initiation of breast-feeding ${ }^{(20)}$. A total of 210 primary studies were analysed independently to identify a list of interventions which had some likelihood of effectiveness, lack of effectiveness or adverse effects. Studies evaluating public health interventions were limited to developed country settings to reflect issues of applicability to the UK and other developed country settings.

This initial assessment generated 110 studies evaluating interventions which were subjected to formal quality appraisal. The quality of each study was assessed using recognised appraisal criteria appropriate to each study design $^{(21)}$. Each study was given an overall quality rating using the NICE quality assessment framework for randomised controlled trials (RCT) ${ }^{(22)}$, including adaptation as appropriate for controlled trial and before-after study designs ${ }^{(23,24)}$. Studies rated as having 'few or no criteria fulfilled whereby the conclusions of the study are thought likely or very likely to alter ${ }^{\text {(22) }}$ were excluded. The resulting seventy studies examining interventions of effectiveness, lack of effectiveness or adverse effects were all considered to be of sufficiently good quality to ensure confidence in the study findings and generalisable to UK settings. These studies examined twenty-five types of intervention for potential implementation in, or removal from, practice for the promotion of the initiation or duration of breast-feeding, with specific reference to women with low breast-feeding rates.

The twenty-five types of intervention formed the basis of the consultation phase to develop the evidence-based interventions into recommendations for practice. The consultation process was devised to reflect organisation of health care in UK settings and might be different in other developed country settings. It comprised four main stages: (i) pilot consultation; (ii) electronic consultation; (iii) fieldwork meetings; and (iv) workshops. Full details are given in elsewhere ${ }^{(16)}$. The pilot consultation phase was undertaken through informal workshop discussions at three national maternal and/or child health conferences. It identified the need to include three policyrelated interventions which, although having a limited formal evidence base, participants considered were important to the field of breast-feeding promotion. A web-based electronic consultation was then undertaken to seek views of practitioners in a broad range of professional, health service and consumer networks. Specifically, practitioners were asked to rate each intervention in terms of its likely impact and feasibility in practice. This generated 516 completed electronic questionnaires. Three fieldwork meetings were undertaken to explore responses to the questionnaire from community-based health professionals and organisations working in lowincome areas and with potentially limited Internet access. The final stage comprised three half-day workshops in areas of high deprivation, ethnic representation and geographical diversity. The eighty-nine participants at the workshops represented a cross-section of practitioners in terms of seniority, acute and primary care sectors, and health and health-related sectors, plus a small number of service user representatives, service managers and commissioners, and national policy leads. The main focus 
of the workshops was to consider the impact and feasibility ratings generated from the earlier consultation phases and to identify barriers to effectiveness and strategies for change.

On completion of this second stage, the findings from both the formal evidence base and consultation input were synthesised to produce a draft report for review by key stakeholders using the NICE consultation framework; details of the ways in which the synthesis was conducted are given in elsewhere ${ }^{(16)}$. This third stage proved valuable as it served to highlight the strong consensus for the proposed recommendations to promote breast-feeding, including clear priorities for recommendations which require universal implementation at a national level, compared with those which are likely to be of differing importance in local settings. This final stage also afforded the opportunity to include further evidence of effectiveness from more recent evaluations of interventions where earlier evidence had been indicative but inconclusive. This iterative process, which drew on both the strengths of the evidence base and the consensus of a wide range of experienced practitioners and key stakeholders in the field of breast-feeding promotion, underpins the strength of the resulting recommendations.

\section{Results}

Twenty-five recommendations were agreed. Priority groups for action were identified as disadvantaged white women, particularly teenage women, first-time mothers or lone parents based on the particularly low breastfeeding rates among these groups. These recommendations, although specifically aimed to increase initiation and duration rates in the UK, may be relevant to other countries where breast-feeding rates and the cultural context are similar.

Three complementary and necessary categories of recommendations emerged: public health policy; mainstream clinical practice; and local interventions.

\section{Recommendations for public bealth policy}

There was clear consensus on the need for strategic policy recommendations which aim to achieve appropriate policy and cultural environments in which health and other service organisations operate to promote breast-feeding. These recommendations were seen as prerequisites to other actions, to enable interventions to work and remove socio-cultural barriers. Specifically, the following national recommendations were identified:

- A comprehensive, coordinated, national, regional and local breast-feeding strategy and policies, including adequate financial incentives and monitoring and evaluation systems which account for maternal ethnicity and deprivation.
- National media campaigns and celebrity endorsements promoting breast-feeding.

- Inclusion of breast-feeding education in the national curriculum for primary and secondary schools, parenting programmes and child development courses targeting pupils with low academic attainment.

- Policy and practice to support breast-feeding in public.

- Employment policy and practices to support breastfeeding.

- Government endorsement of the WHO Code on Marketing of Breast Milk Substitutes (1981) and subsequent resolutions.

\section{Recommendations for mainstream clinical practice}

The following recommendation was identified as the single, most fundamental intervention to achieve increases in initiation and duration rates of breast-feeding for all women, regardless of income, ethnicity, location of birth or duration of hospital stay. Routine implementation of this multifaceted intervention was also felt to be likely to reduce duplication of effort and achieve greater efficiencies and streamlined practice. This intervention is therefore recommended as core to breast-feeding promotion for all hospital and community organisations in the UK.

WHO/UNICEF Baby Friendly Initiative in hospital and community services

- The WHO/UNICEF Baby Friendly Initiative (BFI) should be implemented as routine practice across maternity hospitals. All maternity hospitals should be encouraged to attain the BFI Full Accreditation Award and hospitals with a BFI Certificate of Commitment should progress to the BFI Full Accreditation Award, to increase breast-feeding initiation for all women.

- The BFI in the community provides a recognised and accredited framework for routine practice across community health services to increase initiation and duration of breast-feeding for all women.

Strong consensus was achieved on the need for the following two sets of recommendations to be implemented as routine policy and practice for the provision of appropriate clinical care to promote and support breastfeeding. Several of these recommendations are, in fact, an integral part of the BFI in hospital and community services as recommended above.

Changes to policy and practice for clinical care in hospital and community

- In order to increase duration rates of any and exclusive breast-feeding among all women, routine policy and practice for clinical care in hospital and community should:

- Support effective positioning and attachment, using a predominantly 'hands off' approach. 
- Encourage unrestricted baby-led breast-feeding which helps prevent engorgement, and for women experiencing mastitis, encourage regular breast drainage and continued breast-feeding.

- Encourage the combination of supportive care, teaching breast-feeding technique, sound information and reassurance for breast-feeding women with 'insufficient milk'.

Changes to abandon specific policy and practice for clinical care in hospital and community

- In order to increase the duration of any and exclusive breast-feeding among all women, routine policy and practice for clinical care in hospital and community settings should abandon (or continue to abandon):

- Restriction of the timing and/or frequency of breast feeds during immediate postnatal care.

- Restriction of mother-baby contact from birth onwards during immediate postnatal care.

- Supplemental feeds given routinely or without medical reason in addition to breast feeds.

- Separation of babies from their mothers for the treatment of jaundice.

- Provision of hospital discharge packs and any informational material given to mothers which contain promotion for artificial feeding, including the advertising of 'follow on' artificial milks to mothers of new babies.

\section{Recommendations for local interventions}

Further individual interventions have been shown to be effective at increasing the initiation and/or duration of any and/or exclusive breast-feeding among different population groups in different settings and were considered feasible for implementation in England and Wales and similar developed country settings. The appropriateness and relevance of each intervention are likely to vary depending on the specific needs of population groups within each locality. This issue was considered to be of such importance, it has been framed in the following overarching recommendation:

- When implementing interventions to increase breastfeeding initiation and continuation rates, each locality should consider the best package of interventions to address the diverse needs of their local population group(s). The decision should be informed by the views of practitioners and service users. Where appropriate, interventions should be targeted towards those groups where the rates are lowest; in the UK, that is disadvantaged white women, in particular those who are teenagers or lone parents.

\section{Education and/or support programmes}

The following specific recommendations provide a basis for stakeholders to select the best package of interventions to meet local population needs in addition to the core recommendation above.

- An appropriate mix of the following education and support programmes should be routinely delivered by both health professionals/practitioners and peer supporters in accordance with local population needs:

- Informal, practical breast-feeding education in the antenatal period should be delivered in combination with peer support programmes to increase initiation and duration rates among women on low incomes.

- A single session of informal, small group and discursive breast-feeding education should be delivered in the antenatal period (including topics like the prevention of nipple pain and trauma) to increase initiation and duration rates among women on low incomes.

- Additional, breast-feeding specific, practical and problem-solving support from a health professional/practitioner should be readily available in the early postnatal period to increase duration rates among all women who wish to breast-feed.

- Peer support programmes should be offered to provide information and listening support to women on low incomes in either the antenatal or both the antenatal and postnatal periods to increase initiation and duration rates.

\section{Complementary telephone peer support}

- Peer or volunteer support should be delivered by telephone to complement face-to-face support in the early postnatal period to increase duration rates among women who want to breast-feed, regardless of income.

\section{Education and support from one professional}

- Breast-feeding education and support from one professional should be targeted to women on low incomes to increase their rates of exclusive breast-feeding.

\section{Education and support through the first year}

- One-to-one needs-based breast-feeding education in the antenatal period combined with postnatal support through the first year should be available to increase intention, initiation and duration rates, particularly among white, low-income women.

\section{Media programmes}

- Local media programmes should be developed to target teenagers to improve attitudes towards breast-feeding.

\section{Strategies for effective implementation of recommendations}

The following strategies for effective implementation were identified for consideration by key stakeholders 
including commissioning bodies, government health authorities, health-care organisations and practitioners in primary, community and acute settings. In England and Wales for example, key stakeholders would include Strategic Health Authorities, NHS Trusts and practitioners including pharmacists, Sure Start, Children's Centres and voluntary services. Full details of strategies for effective implementation specific to each recommendation are available in the NICE report ${ }^{(15)}$.

- The BFI provides a recognised and accredited framework and principles for effective implementation of both hospital- and community-based recommendations to promote and support breast-feeding. Consistency of quality care is essential for both hospital and community staff, given shorter hospital stays and increasing numbers of home births for many new mothers.

- Financial support is required to assist health-care organisations with costs of involvement in BFI.

- Additional training of registered and pre-registered health professionals is essential to the success of all recommendations. The BFI provides recognised and accredited training courses for these purposes.

- Financial incentives and support strategies to achieve adequate staffing levels and training staff are prerequisites for the effective delivery of care.

- A national network of fully funded local, regional and national breast-feeding coordinators is essential for effective implementation of multidisciplinary care.

- Strategies to recruit and retain appropriate pools of peer or volunteer supporters are needed, including provision of formal salaries, paid incentives and/or honorary contract schemes, and supervision to ensure quality of the service. Voluntary organisations provide recognised training courses for these purposes.

- Strategies to provide adequate financial support for existing peer support schemes are needed in line with funding policy and practice for other contracted-out services.

- Funding for local media campaigns is essential to change underlying attitudes to breast-feeding by portraying it as 'normal'.

- High-level support from managers is essential to enable work across sectors and disciplines, and to change accepted patterns of working.

- Ongoing monitoring of rates of infant feeding at national and local levels, with agreed definitions and timing of follow-up, combined with socio-economic data, is needed. National-level support is required for the development of agreed definitions and mechanisms for collecting and reporting local, regional and national data.

\section{Discussion}

The evidence base of effectiveness on which these recommendations are based draws on studies conducted in developed country settings and included in systematic reviews conducted prior to 2005. These reviews demonstrated the limitations of the evidence base, particularly gaps in evaluations of policy and more complex, multifaceted interventions, as well as concerns regarding the quality of many studies. New Cochrane review evidence of the effectiveness of local interventions has demonstrated consistent support for the effectiveness of education and/or peer support interventions to promote the initiation of breast-feeding ${ }^{(25)}$. This was based on studies conducted among low-income women in the USA from diverse ethnic backgrounds, with different feeding intentions and typically low breast-feeding rates. While the quality of this evidence is reliable, its scope is limited in terms of its single country setting and the types of intervention which are amenable to evaluation using an RCT methodology. More innovative approaches to appropriate and affordable evaluation of complex, health promotion interventions ${ }^{(26)}$ are needed to address this ongoing limitation of the evidence base.

The gaps in the evidence base for more complex and national policy interventions have not been addressed in recent years, possibly as a result of cost implications for evaluation of such strategies, or possibly because breastfeeding promotion is not always a priority for health or research agencies ${ }^{(27)}$. The extensive consultation process we conducted in the present work aims to address this gap by drawing on the first-hand experience of practitioners, service users, managers and commissioners.

The public health recommendations reported here were published in a document to accompany the NICE clinical guideline on postnatal care in July $2006^{(28)}$. The postnatal care clinical guideline aimed to make recommendations for the essential care that every woman should receive in the first 6-8 weeks postpartum, including clinical best practice to support individual women to start and continue to breast-feed successfully. The public health recommendations reported here aim to complement the guideline by indicating the essential interventions which influence the wider policy, cultural and organisational environments in which more women from different population groups can choose and effectively implement their decision to start and continue to breast-feed their baby for as long as they wish. It is notable that since these reports were published ${ }^{(15,28)}$, the English Department of Health has invested an extra $£ 2$ million into the UK BFI to improve breast-feeding rates in the most deprived areas $^{(29)}$. These initiatives are supported by improved data collection measures to monitor progress on improvements in the prevalence of breast-feeding at 6-8 weeks ${ }^{(29,30)}$. A national strategy to support and promote breast-feeding in England is, however, still lacking.

The comprehensive nature of these public health recommendations has arisen from a variety of key issues highlighted in the consultation process. First, participants clearly identified the need for a strategic, national 
approach to the issues. They indicated that national policy directives are needed, as part of an overall national breastfeeding strategy, to address many of the barriers experienced by practitioners when trying to work across sectors, organisations and professional groups. Approaches included training and supervision, workforce capacity issues, and recruitment and retention of a pool of trained and adequately supervised peer supporters, related to different interventions. National and regional commitment, support and guidance were noted as necessary to address these issues for local implementation to fit with local patterns of service provision.

Second, the factors influencing breast-feeding rates within different population groups in developed country settings are highly diverse and complex ${ }^{(15,31)}$. The decision to breast-feed for a white, pregnant teenager living in a low-income area in England, for example, is likely to be influenced by moral concerns regarding embarrassment of breast-feeding in public ${ }^{(32)}$. This decision contrasts with the practical decision to stop breast-feeding for a mother returning to work in England, where compliance with international standards for support in the workplace is lowest in the European Union ${ }^{(33)}$. Diverse strategies are therefore needed to create the appropriate socio-cultural, workplace, community and health-care environments to effectively promote and support breast-feeding in developed country settings ${ }^{(31)}$.

It is perhaps not surprising, therefore, that both the evidence base ${ }^{(17,18)}$ and the consensus among the participants in this consultation ${ }^{(15)}$ indicate the importance of multifaceted strategies to raise initiation and duration rates. Multifaceted strategies may refer to a single intervention which has several components delivered to the same target group at the same time, for example the BFI; or to combined education and peer support interventions. Alternatively, multifaceted strategies may refer to combined implementation of complementary policy and programme interventions to different target groups over a period of time. For example, the limited evidence of effectiveness and expert opinion attribute the substantive and sustained increases in breast-feeding rates in Norway to increased paid maternity leave, changes to maternity ward practices and mainstream peer support ${ }^{(34,35)}$. This is also consistent with international consensus on the most effective approaches to health promotion in developed countries ${ }^{(36-38)}$.

The need for a long-term commitment to the promotion of breast-feeding was also seen to be essential to enable changes in societal attitudes towards breast-feeding and cultural changes within health-care organisations to be translated into significant increases in breast-feeding rates. This is consistent with the evidence base for strategies promoting changes in lifestyle which tend to be demonstrated in the medium to long term ${ }^{(39-41)}$ and in association with increased length of participation in the programme ${ }^{(42,43)}$.
Monitoring the impact of effective interventions also requires systematic routine data collection on breastfeeding initiation and duration, collected at a level that will enable analysis of socio-economic, ethnic and regional factors, such as postcode level. Baseline data will be needed to assess the impact of interventions and to identify localities with particular problems. Such data will enable the monitoring of progress towards newly developed local, regional and national targets ${ }^{(44)}$.

Finally, the relevance of these recommendations has been demonstrated by the speed of their uptake in national and local initiatives in the UK. Since the publication of the main report, many of the implementation points have been adopted. Recommendations informed the content of the national UK Breastfeeding Manifesto (www.breastfeedingmanifesto.org.uk) and the new UK BFI community intervention ${ }^{(45)}$.

\section{Recommendations for research}

The most notable gaps in the evidence base from developed country settings include:

- Impact studies of relevant national health and welfare policies.

- Large-scale, high-quality evaluations of the BFI in the community, mass media promotion and social marketing.

Further testing and development of recently debated methodologies for evaluations of complex breast-feeding promotion policies and interventions ${ }^{(27,46-48)}$ would also make a useful contribution to future research in public health and health promotion.

In conclusion, the development, implementation, monitoring and evaluation of an overarching national breast-feeding strategy are fundamental to achieving significant improvements in breast-feeding practices. Such a strategy is likely to facilitate the greatest gains at the local level among women with typically lower breast-feeding rates and associated poorer maternal and child health outcomes, and thereby to address inequalities in health.

\section{Acknowledgements}

Sources of funding: The original research was funded by the National Centre for Health and Clinical Excellence, grant number HDA874. Conflict of interest declaration: No conflicts of interest are known for any authors contributing to this manuscript. The submission of this paper represents original work that has not been published previously in any journal, is not being considered by another journal, and that being accepted for Public Health Nutrition will not be published elsewhere in the same form, in English or in any other language, without the written consent of the Nutrition Society. Each author has seen and approved the contents of the submitted manuscript. Contribution of authors: L.D. - lead 
researcher on original research project and preparation of manuscript; M.J.R. - principal investigator for original research project and second main contributor for preparation of manuscript; A.M. - lead researcher on consultation process for original research project and contributing author in preparation of manuscript; F.M. researcher on original research project and contributing author in preparation of manuscript; G.H. - facilitator for workshops on consultation process and contributing author in preparation of manuscript; J.T. - researcher on original research project and contributing author in preparation of manuscript.

\section{References}

1. Ip S, Chung M, Raman G, Chew P, Magula N, DeVine D, Trikalinos T \& Lau J (2007) Breastfeeding and Maternal and Infant Health Outcomes in Developed Countries. Boston, MA: Agency for Healthcare Research and Quality, US Department of Health and Human Services.

2. Quigley MA, Cumberland P, Cowden JM \& Rodrigues LC (2006) How protective is breast feeding against diarrhoeal disease in infants in 1990s England? A case-control study. Arch Dis Child 91, 245-250.

3. World Health Organization (2003) Global Strategy for Infant and Young Child Feeding. Geneva: WHO.

4. Department of Health (1995) Breastfeeding: Good Practice Guidance to the NHS. Prepared in consultation with National Breastfeeding Working Group. London: Department of Health.

5. Collaborative Group on Hormonal Factors in Breast Cancer (2002) Breast cancer and breastfeeding: collaborative reanalysis of individual data from 47 epidemiological studies in 30 countries, including 50302 women with breast cancer and 96973 women without the disease. Lancet 360, 187-195.

6. Bolling K, Grant C, Hamlyn B \& Thornton A (2007) Infant Feeding Survey 2005. A survey conducted on behalf of The Information Centre for health and social care and The UK Health Departments by BMRB Social Research. The Information Centre; available at http://www.ic.nhs.uk/webfiles/ publications/ifs06/2005\%20Infant $\% 20$ Feeding $\% 20$ Survey $\%$ 20\%28final\%20version\%29.pdf

7. Hamlyn B, Brooker S, Oleinokova K \& Wands S (2002) Infant Feeding 2000. A survey conducted on behalf of the Department of Health, the Scottish Executive, The National Assembly for Wales and the Department of Health, Social Services and Public Safety in Northern Ireland. London: The Stationery Office.

8. Lanting CI, Herschderfer K, van Wouwe JP\& Rejneveld SA (2002) Peiling melkvoeding van zuigelingnen 2000/2001 en het effect van certificering op de borstvoedingscijfers. The WHO Global Data Bank on Breastfeeding and Complementary Feeding. http://apps.who.int/research/ iycf/bfcf/bfcf.asp?menu $=21 \& \mathrm{cID}=\mathrm{NLD} \& \mathrm{iID}=\& \mathrm{yID}=\& \mathrm{ok}=$ true (accessed June 2009).

9. Crost M \& Kaminski M (1998) L'allaitement maternal a la maternite en France en 1995. Enquete nationale perinatale. Arch Pediatr 5, 1316-1326. The WHO Global Data Bank on Breastfeeding and Complementary Feeding. http://apps. who.int $/$ research/iycf/bfcf/bfcf.asp? menu $=21 \& c I D=$ FRA-NLD \&iID $=\& y I D=\& o k=$ true (accessed June 2009).

10. Li R, Zhao Z, Mokdad A, Barker L \& Grummer-Strawn L (2003) Prevalence of breastfeeding in the United States: the 2001 National Immunization Survey. Pediatrics 111, 1198-1201.
11. Ross Laboratories (2003) Mothers Survey, Ross Products Division of Abbott. Breastfeeding Trends - 2003. http:// www.kellymom.com/writings/ross-data.html (accessed June 2009).

12. Griffiths LJ, Tate AR \& Dezateux C; Millennium Cohort Study Child Health Group (2005) The contribution of parental and community ethnicity to breastfeeding practices: evidence from the Millennium Cohort Study. Int $J$ Epidemiol 34, 1378-1386.

13. Thomas M \& Avery V (1997) Infant Feeding in Asian Families. London: The Stationery Office.

14. Kelly YJ, Watt RG \& Nazroo JY (2006) Racial/ethnic differences in breastfeeding initiation and continuation in the United Kingdom and comparison with findings in the United States. Pediatrics 118, 1428-1435.

15. Dyson L, Renfrew M, McFadden A, McCormick F, Herbert G \& Thomas J (2006) Promotion of breastfeeding initiation and duration: Evidence into practice briefing. http:// www.nice.org.uk/niceMedia/pdf/EAB_Breastfeeding_final_ version.pdf (accessed June 2009).

16. Renfrew MJ, Dyson L, Herbert G, McFadden A, McCormick F, Thomas J \& Spiby H (2008) Developing evidence-based recommendations in public health - incorporating the views of practitioners, service users and user representatives. Health Expect 11, 3-15.

17. Fairbank L, O'Meara S, Renfrew MJ, Woolridge M, Sowden AJ \& Lister-Sharp D (2000) A systematic review to evaluate the effectiveness of interventions to promote the initiation of breastfeeding. Health Technol Assess 4, 1-171.

18. Renfrew MJ, Dyson L, Wallace L, D'Souza L, McCormick F \& Spiby H (2005). The Effectiveness of Public Health Interventions to Promote the Duration of Breastfeeding: Systematic Reviews of the Evidence. London: National Institute for Health and Clinical Excellence; available at http://www.nice.org.uk/niceMedia/pdf/Breastfeeding_vol_1. pdf, http://www.nice.org.uk/niceMedia/pdf/Breastfeeding_ vol_2.pdf

19. Tedstone A, Dunce N, Aviles M, Shetty P \& Daniels L (1998) Effectiveness of Interventions to Promote Healthy Feeding in Infants Under One Year of Age: A Review. Health Promotion Effectiveness Reviews. London: Health Education Authority.

20. Protheroe L, Dyson L, Renfrew MJ, Bull J \& Mulvihill C (2003) The Effectiveness of Public Health Interventions to Promote the Initiation of Breastfeeding. Evidence Briefing. London: Health Development Agency.

21. Centre for Reviews and Dissemination (2001) Undertaking Systematic Reviews of Research on Effectiveness: CRD's Guidance for Those Carrying Out or Commissioning Reviews. CRD Report no. 4, 2nd ed. York: University of York, CRD.

22. National Institute for Clinical Excellence (2004) Guideline Development Methods, Information for National Collaborating Centres and Guideline Developers. London: NICE.

23. Weightman AL, Ellis S, Cullum A, Sander L \& Turley R (2005) Grading Evidence and Recommendations for Public Health Interventions: Developing and Piloting a Framework. London: Health Development Agency; available at http://www.nice.org.uk/niceMedia/docs/grading_evidence. pdf

24. Kelly MP, Chambers J, Huntley J \& Millward L (2004) Method 1 for the Production of Effective Action Briefings and Related Materials. HDA Evidence into Practice. London: Health Development Agency.

25. Dyson L, McCormick FM \& Renfrew MJ (2005) Interventions for promoting the initiation of breastfeeding. Cochrane Database Syst Rev issue 2, CD001688.

26. Hawe P, Shiell A \& Riley T (2004) Complex interventions: how 'out of control' can a randomised trial be? BMJ 328, 1561-1563. 
27. Renfrew MJ, Spiby H, D'Souza D, Wallace LM, Dyson L \& McCormick F (2007) Rethinking research in breast-feeding: a critique of the evidence base identified in a systematic review of interventions to promote and support breastfeeding. Public Health Nutr 10, 726-732.

28. National Institute for Health and Clinical Excellence (2006) Routine Postnatal Care of Women and Their Babies. NICE Clinical Guideline no. 37. Developed by the National Collaborating Centre for Primary Care. http://www.nice. org.uk/CG037 (accessed June 2009).

29. UNICEF UK Baby Friendly Initiative (2008) UNICEF UK's Baby Friendly Initiative welcomes Government announcement to invest $£ 2 \mathrm{~m}$ to help more women breastfeed. News item 05 August 2008. http://www.babyfriendly.org.uk/ items/item_detail.asp?item $=535$ (accessed June 2009).

30. Department of Health (2008) Breastfeeding at 6-8 weeks. Data Collection Guidance. http://www.dh.gov.uk/en/ Healthcare/Maternity/Maternalandinfantnutrition/DH_085657 (accessed September 2008).

31. European Commission (2004) EU Project on Promotion of Breastfeeding in Europe. Protection, promotion and support of breastfeeding in Europe: a blueprint for action. Directorate Public Health and Risk Assessment, Luxembourg. http://www.iblce-europe.org/Download/Blueprint/ Blueprint $\% 20$ English.pdf (accessed July 2009).

32. McMillan B, Conner M, Woolridge M, Dyson L, Green J, Renfrew M, Bharj K \& Clarke G (2007) Predicting breastfeeding in women living in areas of economic hardship: explanatory role of the theory of planned behaviour. Psychol Health 23, 767-788.

33. Nicoll A, Thayaparan B, Newell M \& Rundall P (2002) Breast feeding policy, promotion and practice in Europe. Results of a survey with non-governmental organizations. J Nutr Environ Med 12, 255-264.

34. Helsing E \& Kjäernes U (1985) A silent revolution - changes in maternity ward routines with regard to infant feeding in Norway 1973-1982. Acta Paediatr Scand 74, 332-337.

35. Austveg B \& Sundby J (1995) Empowerment of Women: The Case of Breastfeeding in Norway. Oslo: Norwegian Breastfeeding Association.

36. ECSC-EC-EAEC (2000) The Evidence of Health Promotion Effectiveness, Shaping Public Health in a New Europe. A Report for the European Commission by the International Union for Health Promotion and Education, 2nd ed. Brussels/Luxembourg: ECSC-EC-EAEC.
37. World Health Organization (1998) Resolution of the Executive Board of the WHO on health promotion. Health Promot Int 13, 266.

38. Haglund BJA, Finer D \& Tillgren P (editors) (1996) Creating Supportive Environments for Health: Stories from the Third International Conference on Health Promotion, Sundsvall, Sweden. Geneva: WHO.

39. Avenell A, Broom J, Brown TJ, Poobalan A, Aucott L, Stearns SC, Smith WCS, Jung RT, Campbell MK \& Grant AM (2004) Systematic review of the long-term effects and economic consequences of treatments for obesity and implications for health improvement. Health Technol Assess 8, 1-182.

40. Foxcroft DR, Ireland D, Lister-Sharpe DJ, Lowe G \& Breen R (2003) Longer-term primary prevention for alcohol misuse in young people: a systematic review. Addiction 98, 397-411.

41. West R, McNeill A \& Raw M (2000) Smoking cessation guidelines for health professionals: an update. Thorax $\mathbf{5 5}$, 987-999.

42. Metcoff J, Costiloe P, Crosby WM, Dutta S, Sandstead HH, Milne D, Bodwell CE \& Majors SH (1985) Effect of food supplementation (WIC) during pregnancy on birth weight. Am J Clin Nutr 41, 933-947.

43. Rush D, Sloan NL, Leighton J et al. (1988) The National WIC Evaluation: evaluation of the Special Supplemental Food Program for Women, Infants and Children. V. Longitudinal study of pregnant women. Am J Clin Nutr 48, 2 Suppl., 439-483.

44. Nutbeam D \& Wise M (1996) Planning for Health for All: international experience in setting health goals and targets. Health Promot Int 11, 219-225.

45. UNICEF UK Baby Friendly Initiative (2008) Community Initiative Review - results of the consultation. News item 22 July 2008. http://www.babyfriendly.org.uk/items/item_ detail.asp?item $=534$ (accessed February 2009).

46. Oakley A, Strange V, Bonell C, Allen E \& Stephenson J (2006) Process evaluation in randomised controlled trials of complex interventions. BMJ 332, 413-416.

47. Medical Research Council (2000) A Framework for the Development and Evaluation of Randomised Controlled Trials for Complex Interventions to Improve Health. London: MRC; available at http://www.mrc.ac.uk/Utilities/ Documentrecord/index.htm?d=MRC003372.

48. Nutbeam D (1998) Evaluating health promotion - progress, problems and solutions. Health Promot Int 13, 27-44. 